\title{
Potential Role of Zinc in the COVID-19 Disease Process and its Probable Impact on Reproduction
}

\author{
Ramya Sethuram ${ }^{1} \cdot$ David Bai $^{1} \cdot$ Husam M. Abu-Soud ${ }^{1,2,3}$ (D) \\ Received: 18 August 2020 / Accepted: 16 November 2020 / Published online: 7 January 2021 \\ (C) Society for Reproductive Investigation 2021
}

\begin{abstract}
COVID-19 (coronavirus disease 2019) is the current world health crisis, producing extensive morbidity and mortality across all age groups. Given the established roles of zinc in combating oxidative damage and viral infections, zinc is being trialed as a treatment modality against COVID-19. Zinc also has confirmed roles in both male and female reproduction. The possible depletion of zinc with the oxidative events of COVID-19 is especially relevant to the fertility of affected couples. This review aims to present the pathophysiology of COVID-19, especially in relation to reproductive function; the role of zinc in the COVID19 disease process; and how zinc depletion in concert with cytokine storm and reactive oxygen species production could affect reproduction. It also highlights research areas to better the understanding of COVID-19 and its impact on fertility and potential ways to mitigate the impact.
\end{abstract}

Keywords Coronavirus $\cdot$ Covid-19 $\cdot$ Reactive oxygen species $\cdot$ Zinc $\cdot$ Infertility

\begin{tabular}{ll}
\multicolumn{2}{l}{ Abbreviations } \\
COVID-19 & Coronavirus disease-19 \\
ROS & Reactive oxygen species \\
MPO & Myeloperoxidase \\
$\mathrm{H}_{2} \mathrm{O}_{2}$ & Hydrogen peroxide
\end{tabular}

\section{Zinc Deficiency and COVID-19}

The association between zinc deficiency and worse outcomes of respiratory viral infections has been established [1]. Hence, zinc is being trialed as a nutritional supplement that is being used either as a stand-alone intervention or in conjunction with other nutrients for the prophylaxis and the treatment of the coronavirus disease 2019 (COVID-19) infection [2]. The

Husam M. Abu-Soud

habusoud@med.wayne.edu

1 Department of Obstetrics and Gynecology, The C.S. Mott Center for Human Growth and Development, Wayne State University School of Medicine, 275 E. Hancock, Detroit, MI 48201, USA

2 Department of Physiology, Wayne State University School of Medicine, Detroit, MI 48201, USA

3 Department of Microbiology, Immunology and Biochemistry, Wayne State University School of Medicine, Detroit, MI 48201, USA well-documented roles of zinc in preventing cell damage and its anti-viral properties are helpful in explaining the potential role of zinc in COVID-19 management [3]. Furthermore, there is a degree of overlap between the symptomatology of COVID-19 and that of zinc deficiency.

Like the multiorgan damage and dysfunction characteristic of severe COVID-19 progression, zinc deficiency has farreaching impacts, affecting the nervous, cardiovascular, thymic, immune, and endocrine systems [4]. Acute effects of zinc deficiency include hair loss, diarrhea, delayed sexual maturation, impotence, hypogonadism in males, and skin lesions [5]. Also, zinc deficiency has been associated with a higher risk of atherosclerosis, diabetes, rheumatoid arthritis, neurodegenerative disease, and obesity secondary to unrestrained chronic inflammation [6-8]. These pathologies, in turn, have been correlated with increased risk for COVID-19 related complications. To a certain degree, patients with these conditions are also likely to have fertility-related and pregnancy-associated complications. Pregnant women infected with COVID-19 have been documented to have poorer outcomes resulting in miscarriages, preterm births, cesarean sections, and perinatal deaths $[9,10]$. Hence, reproduction at the time of COVID-19 is fraught with risks and the epigenetic changes on the male and female reproductive organs secondary to COVID-19 exposure is unknown. Reports indicating adverse effects of COVID-19 on male and female gametogenesis are emerging 
[11]. The potential impacts of SARS CoV-2 on the sperm and the oocyte and consequentially the embryo quality remains to be fully investigated.

\section{Cytokine Storm, Reactive Oxygen Species, and Zinc}

In COVID-19 infections, acute phase response and the resultant cytokine storm are causative factors for multiorgan damage. The deluge of inflammatory markers secondary to the cytokine storm results in the formation of unlimited quantities of reactive oxygen species (ROS) produced through activation of the mitochondrial respiratory chain, cytochrome P450 enzymes, peroxisomal fatty acid metabolism, and flavoprotein oxidases. In addition, COVID-19 infection is associated with the generation of interleukins, such as IL-6, and tumor necrosis factor (TNF $\alpha$ ), which increase neutrophil myeloperoxidase (MPO) activity [12]. Excessive MPO activity can generate free iron through hemoprotein heme destruction, and free iron can in turn mediate the Fenton reaction to further produce ROS, including the highly reactive hydroxyl radical $\left({ }^{\circ} \mathrm{OH}\right)[13,14]$. Importantly, overproduction of each of the inflammatory markers and ROS, separately or collectively, has various degrees of impact on the male and the female reproductive system. For example, in the oocytes and embryos, even shortlived ROS such as $\bullet \mathrm{OH}\left(t_{1 / 2}=10^{-9} \mathrm{~s}\right)$, superoxide $\left(\mathrm{O}_{2}{ }^{{ }^{-}}\right)$ $\left(t_{1 / 2}=5 \mathrm{~s}\right)$, and peroxynitrite $\left(\mathrm{ONOO}^{-}\right)\left(t_{1 / 2}=10 \sim 20 \mathrm{~ms}\right)$ have been shown to produce instant and irreversible effects by disimpacting the oocyte spindle and altering the chromosomal alignment [14, 15]. Similarly, mammalian oocytes exposed to IL-6 have a dose-dependent deterioration in microtubule and chromosomal alignment [16]. However, $\mathrm{H}_{2} \mathrm{O}_{2}$ and hypochlorous acid $(\mathrm{HOCl})$ generated by the neutrophil MPO$\mathrm{H}_{2} \mathrm{O}_{2}$ system are longer-lived signaling molecules that cause oocyte damage in a dose-dependent fashion [17, 18]. Also, sperm oxidative stress and resultant ROS are strongly associated with a significant reduction in fertilization rates and IVF/ ICSI outcomes in mammals [19].

Another possible factor for the observed pathophysiology in critical cases of COVID-19 is a decline in nitric oxide (NO), a key mediator of vasodilation and also an important regulator of oocyte quality and aging [20] (Fig. 1). Nitric oxide bioavailability can decline in the presence of $\mathrm{O}_{2}{ }^{--}$resulting in the generation of $\mathrm{ONOO}^{-}$which results in cell damage. ROS overproduction and its detrimental effects on $\mathrm{NO}$ are also induced by intracellular zinc depletion, which consequentially causes dysfunction of zinc-dependent antioxidant proteins such as superoxide dismutase (SOD), catalases and glutathione (GSH), NO synthase dimer assembly, and the dysfunction of a number of zinc finger proteins, thereby resulting in mitochondrial damage, which further accentuates oxidative stress $[21,22]$. Zinc also serves to inhibit NADPH oxidase and antagonizes redox activity of the transition metals iron and copper, thereby decreasing ROS production [23]. Thus, zinc deficiency has potential impacts to all organ systems during the COVID-19 disease process and could also leave enduring impacts on the oocyte and sperm quality. Hence, supplementation of zinc to women seeking fertility, especially at the time of the COVID-19 pandemic could be valuable in improving oocyte, sperm, and embryo quality.

\section{Zinc Supplementation and COVID-19}

Zinc deficiency places the individual at an increased risk of infections and secondary complications, delayed recovery, decreased wound healing, and increased vulnerability to cell damage from the acute phase response [24]. There is a considerable overlap between the symptomatology of SARS CoV-2 infection and zinc deficiency. Some of the unusual COVID-19 symptoms such as loss of smell and taste are secondary to the enhancement of oxidative stress-mediated by ROS and neutrophil MPO activity and this has been well established in conjunction with zinc deficiency [25]. A comprehensive epidemiological study of childhood mortality identified zinc deficiency as one of the major causes of diarrhea and pneumonia in children [26]. This could also help explain how zinc supplement might help improve outcomes in patients infected with SARS CoV-2. Zinc supplementation in COVID-19 patients could limit the disease process not only by eliminating ROS but also by improving the immune response to the infection. Zinc has anti-inflammatory activity and inhibits NF-KB signaling and regulates $\mathrm{T}$ cell function to limit the cytokine storm. In vitro experiments have demonstrated that zinc possesses anti-viral properties through inhibition of SARS-CoV RNA polymerase. Indirect evidence has also established that zinc may decrease the activity of angiotensin-converting enzyme 2 (ACE2) which is a receptor for SARS COV-2 [27]. It also enhances the resistance of the cell to apoptosis by inhibiting caspase-3,-6,-9 [28]. Anti-viral properties of zinc are also related to the metallothioneins (MTs), zinc-binding proteins, the function of which is to store and transport zinc. The presence of reactive compounds or oxidative stress results in modification of the cysteine sulfur ligands of MTs, thereby releasing zinc ions, which in turn leads to increased intracellular free zinc concentrations. An overexpression of MTs has been established in patients infected with flaviviruses (e.g., yellow fever, HCV) and alphaviruses (Venezuela equine encephalitis virus). MTs may sequester zinc away from the viral metalloproteins, thereby facilitating anti-viral signaling [29]. Also, the zinc finger anti-viral protein (ZAP), a key component in interferonmediated immune response, binds to the $\mathrm{CpG}$ dinucleotides in the viral genomes [30]. Subsequently, ZAP inhibits viral replication and mediates viral genome degradation [31]. 


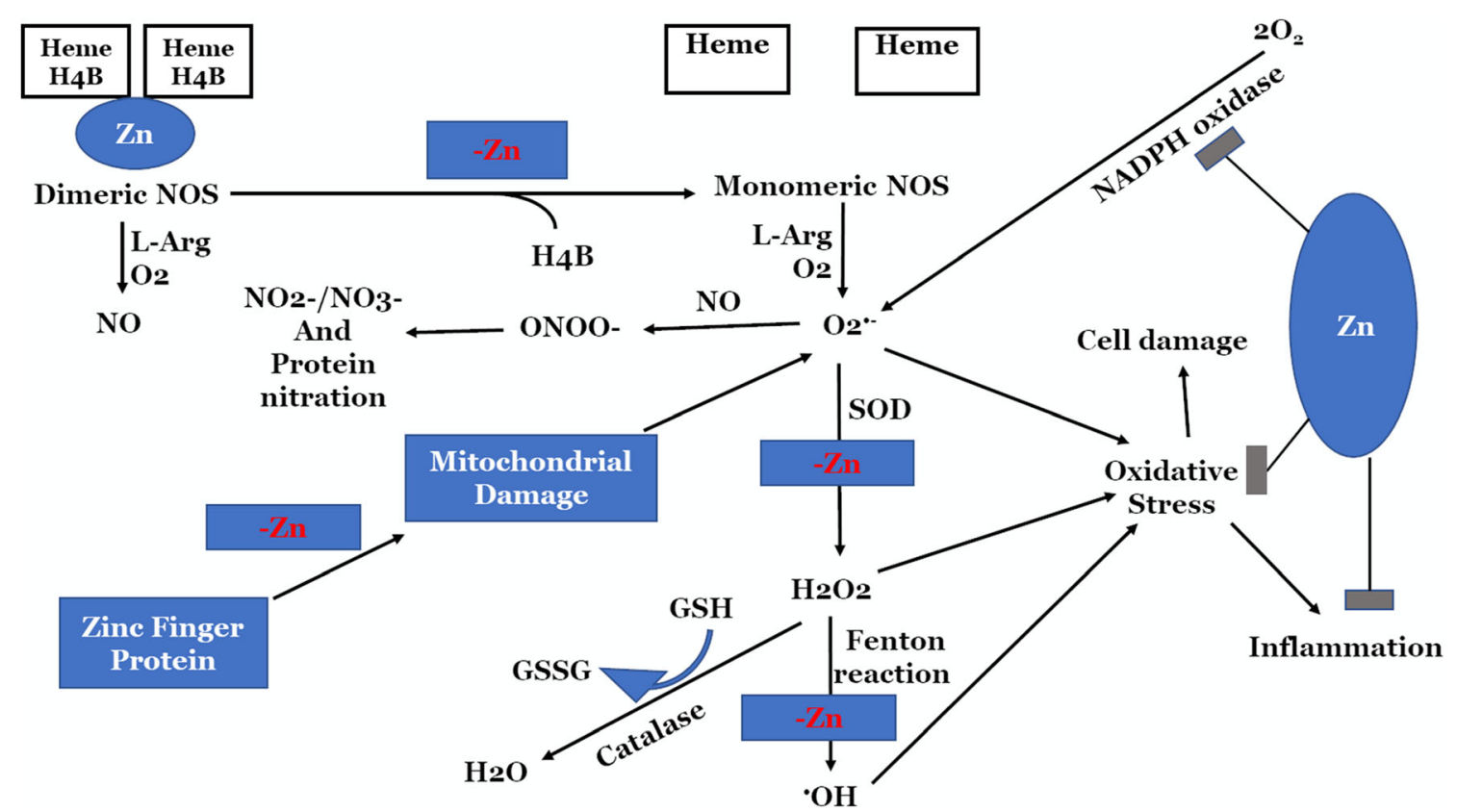

Fig. 1 The relationships between NOS, zinc, ROS, and related pathophysiologies. Zinc is involved in attenuating oxidative events and is also required for NOS dimerization. Zinc deficiency not only directly leads to oxidative stress through increased presence of ROS but also uncouples NOS, causing it to generate superoxide to further compound ROS elevation. These manifest as numerous detrimental conditions
Therefore, zinc has a clearly established role in the immune response to viral infections [32]. Studies show positive effects of therapeutic zinc treatment on viral replication or infectionrelated symptoms of viruses and viral diseases such as rhinovirus-associated cold symptoms, herpesviruses, picornaviridae, flaviviridae, togaviridae, retroviridae: HIV, and papillomaviridae [33].

Current literature on zinc supplementation in COVID -19 is limited to a very small retrospective study in hospitalized patients that did not demonstrate a causal association between zinc supplements and improved prognosis and survival [34]. While larger and more comprehensive studies are urgently needed to inform this discussion, zinc could indeed be of limited value once the patient is sick enough to be hospitalized. After the patient experiences the cytokine storm, the resultant proinflammatory response causes extensive oxidative damage and ROS production. This would deplete intracellular zinc, more rapidly so in zinc-deficient individuals. Hence, the enzymes that help with the clearing up of the ROS elements become nonfunctional, paving way for acute irreversible cell damage. Zinc supplementation, especially by itself, may be insufficient to reverse the process once widespread acute and oxidative cell damage has occurred. However, if administered to COVID-19 infected individuals in the pre-cytokine storm phase, repletion of zinc in the body might help ameliorate COVID-19 progression in the mild and early phases by both suppressing viral replication as well as by preventing cell damage by acting as a pro-antioxidant.

\section{Zinc and Reproduction}

Zinc is an essential element for the functioning of both the male and the female reproductive organs and for completion of meiosis and creating good quality blastocysts. With our current understanding of zinc in the reproductive process, its critical role in determining the sperm, the oocyte, and the embryo quality is well established in mouse and human model $[35,36]$ (Table 1). Zinc chelation in mouse oocytes and embryos has been demonstrated to decrease intra-oocyte zinc concentration, increased intracellular ROS levels, and changes to the oocyte spindle morphology with poorer quality spindles noted at decreasing intracellular zinc levels [37]. Zinc is the key regulator of meiosis in the oocyte. Zinc spark is the phenomenon whereby the post-fertilization concentration of zinc in the zona pellucida increases by $300 \%$. Zinc spark has direct biological consequence as this results in hardening of the zona pellucida which consequentially blocks polyspermy and is associated with better blastocyst and embryo quality [38, 39]. Hence, maternal zinc deficiency in mammals produces effects ranging from infertility, embryo/fetal death, prematurity, decreased postpartum immunity, impaired wound healing, and an increased risk of neurobehavioral abnormalities [40-43]. Zinc deficiency is associated with teratogenesis and intrauterine growth restriction during pregnancy [44-47].

Zinc is also a crucial modulator of male reproductive function. It is a vital anti-inflammatory factor involved in the oxidative metabolism of the sperm. Its other roles include sperm membrane stabilization, capacitation, and acrosomal reaction 
Table 1 Functions of zinc in male and female reproduction

\begin{tabular}{ll}
\hline Functions of zinc in male reproduction & Functions of zinc in female reproduction \\
\hline Oxygen intake of spermatozoa & Sexual maturation \\
Nuclear chromatin condensation & Development of the breast and genitalia \\
Acrosomal reaction & Estrous production \\
Acrosin activity & Oocyte maturation \\
Sperm chromatin stabilization & Cumulus expansion \\
Testicular steroidogenesis & Gene expression in vitro \\
Testosterone synthesis & Maintenance of pregnancy \\
Testicular development & Fetal growth - teratogenesis/IUGR in deficiency \\
Conversion of testosterone to dihydrotestosterone (DHT) & Postpartum immunity and emotional well being \\
\hline
\end{tabular}

$[48,49]$. In the testis, zinc is vital for the production and secretion of testosterone from the Leydig cells, maintaining genomic integrity of the sperm and sperm assembly [50]. Accordingly, zinc deficiency is also associated with low serum testosterone concentrations, primary testicular failure, lessening function of the luteinizing hormone receptor, decreased steroid synthesis, and Leydig cell damage due to oxidative stress [51, 52]. Inflammatory process associated with various disorders and higher body temperature induces ROS and also leads to testicular malfunction and altered sperm production [53]. In smokers and infertile men, increased ROS levels in the seminal plasma result in seminal fluid zinc deficiency which sequentially produces abnormal sperm parameters [54]. We believe that the SARS CoV-2 induced cytokine storm, like cytokine storm in other conditions, would similarly increase ROS in the gametogenic cells and deplete intracellular zinc, potentially resulting in oocyte and sperm damage. Zinc deficiency further showed that it can mediate the ROS overproduction and potentiate oocyte and sperm damage through the same mechanism. Hence, zinc depletion and ROS appear to have a bidirectional relationship resulting in a vicious cycle with one aggravating the effects of another.

\section{Zinc Supplementation in COVID-19 Patients Desiring Fertility}

Although zinc supplementation in COVID-19 patients has been implemented and analyzed to an extent, data regarding the effects of zinc supplementation on the fertility of couples with COVID-19 exposure remains scarce. The effects of zinc supplementation on the oocyte quality are difficult to reciprocate in vivo, as obtaining and analyzing the oocyte is an invasive procedure. However, zinc deficiency has been established to cause disruption of the post-implantation fetal and placental development in mice [55]. Also, the only available literature of in vitro testing on mouse metaphase 2 oocytes has established that zinc deficiency causes oocyte deterioration and embryo damage through a mechanism involving overproduction of ROS [56]. The study of zinc supplementation on sperm quality has been undertaken and has been proven to be of value. Zinc supplementation has been demonstrated to protect against chemotherapy-induced testicular damage, with better sperm counts noted in the group of patients treated with zinc supplementation [57]. Also, supplementation of zinc alongside folic acid significantly improved sperm parameters in subjects post varicocelectomy [58]. In our opinion, supplementation of zinc to both male and female partners seeking fertility during the COVID-19 pandemic could help protect against gametogenic damage, possibly improving embryo quality, and potentially lessening some of the pregnancy complications.

\section{Conclusions}

With the initial advent of the SARS CoV-2 virus infection in March 2020, the American Society of Reproductive Medicine (ASRM) noted the highly infectious nature of the disease and the potential complications associated with pregnancies, and advised suspension of all new treatment cycles and cessation of embryo transfers (https://www.asrm.org/globalassets/asrm/ asrm-content/news-and-publications/covid-19/ covidtaskforce.pdf). However, the current widespread recent resurgence of SARS COV-2 transmission that has currently exceeded 12 million cases in the USA alone, reaffirms the need to practice reproductive health in a COVID-19 environment for the foreseeable future. Given the crucial roles of zinc in reproduction and its beneficial effects as an anti-oxidant and anti-inflammatory agent, a policy of zinc supplementation to men and women aiming to conceive either through natural or through assisted reproduction may prevent mitochondrial damage and avoid the accumulation of ROS in the oocyte and spermatogonia. It may also enhance immunity against the virus, which could in turn improve pregnancy outcomes. In the general population, zinc supplementation could be beneficial in both enhancing immunity and in fighting against the viral disease process. Though higher doses of zinc have been 
used in current COVID-19 clinical trials, until we have robust data, all adults could be supplemented with up to a maximum of $50 \mathrm{mg}$ /day without significant toxic side-effects. Presently, there are multiple studies registered with the WHO that aim to look at the value of zinc, either in the oral or in the intravenous form in patients affected with COVID-19 (https://www.who. int/ictrp/search/en/). The results of these studies, when available, will further elucidate the value of zinc in the setting of COVID-19, especially in the reproductive age group.

\section{Compliance with Ethical Standards}

Research Involving Human Participants/Animals This manuscript did not make use of human or animal participants or samples.

Conflict of Interest The authors declare that they have no conflict of interest.

Informed Consent N/A

\section{References}

1. Roth DE, Richard SA, Black RE. Zinc supplementation for the prevention of acute lower respiratory infection in children in developing countries: meta-analysis and meta-regression of randomized trials. Int J Epidemiol. 2010;39:795-808.

2. Wessels I, Rolles B, Rink L. The potential impact of zinc supplementation on COVID-19 pathogenesis. Front Immunol. 2020;11: 1712.

3. Prasad AS. Zinc: an antioxidant and anti-inflammatory agent: role of zinc in degenerative disorders of aging. J. Trace Elem. Med. Biol. 2014;28:364-71.

4. Yanagisawa $\mathrm{H}$. Zinc deficiency and clinical practice-validity of zinc preparations. Yakugaku Zasshi. 2008 Mar;128(3):333-9.

5. Prasad AS. Zinc deficiency: its characterization and treatment. Met Ions Biol Syst. 2004;41:103-37.

6. Chabosseau P, Rutter GA. Zinc and diabetes. Arch Biochem Biophys. 2016;611:79-85.

7. Olechnowicz J, Tinkov A, Skalny A, Suliburska J. Zinc status is associated with inflammation, oxidative stress, lipid, and glucose metabolism. J Physiol Sci. 2018;68:19-31.

8. Kozlowski H, Luczkowski M, Remelli M, Valensin D. Copper, zinc and iron in neurodegenerative diseases (Alzheimer's, Parkinson's and prion diseases). Coord Chem Rev. 2012;256: 2129-41.

9. Chen H, Guo J, Wang C, Luo F, Yu X, Zhang W, et al. Clinical characteristics and intrauterine vertical transmission potential of COVID-19 infection in nine pregnant women: a retrospective review of medical records. Lancet. 2020a;395:809-15.

10. Dashrath P, Wong JLJ, Lim MXK, Lim LM, Li S, Biswas A, et al. Coronavirus disease 2019 (COVID-19) pandemic and pregnancy. Am J Obstet Gynecol. 2020;222(6):521-31.

11. Segars J, Katler Q, DB MQ, Alexander Kotlyar A, Glenn T, Knight $\mathrm{Z}$, et al. American Society for Reproductive Medicine Coronavirus/ COVID-19 Task Force. Prior and novel coronaviruses, Coronavirus Disease 2019 (COVID-19), and human reproduction: what is known? Fertil Steril. 2020 Jun;113(6):1140-9.

12. Moore JB, June CH. Cytokine release syndrome in severe COVID19. Science. 2020 May 1;368(6490):473-4.
13. Maitra D, Byun J, Andreana PR, Abdulhamid I, Diamond MP, Saed GM, et al. Reaction of hemoglobin with $\mathrm{HOCl}$ : mechanism of heme destruction and free iron release. Free Radic Biol Med. 2011;51(2):374-86.

14. Shaeib F, Banerjee J, Maitra D, Diamond MP, Abu-Soud HM. Impact of hydrogen peroxide-driven Fenton reaction on mouse oocyte quality. Free Radic Biol Med. 2013 May;58:154-9.

15. Banerjee J, Shaeib F, Maitra D, Saed GM, Dai J, Diamond MP, Abu-Soud HM. Peroxynitrite affects the cumulus cell defense of metaphase II mouse oocytes leading to disruption of the spindle structure in vitro. Fertil Steril. 2013;100(2):578-84.

16. Banerjee J, Sharma R, Agarwal A, Maitra D, Diamond MP, AbuSoud HM. IL-6 and mouse oocyte spindle. PLoS One. 2012;7(4): e35535.

17. Khan SN, Shaeib F, Najafi T, Kavdia M, Gonik B, Saed GM, et al. Diffused intra-oocyte hydrogen peroxide activates myeloperoxidase and deteriorates oocyte quality. PLoS One. 2015 Jul 21;10(7):e0132388.

18. Goud AP, Goud PT, Diamond MP, Gonik B, Abu-Soud HM. Reactive oxygen species and oocyte aging: role of superoxide, hydrogen peroxide, and hypochlorous acid. Free Radic Biol Med. 2008 Apr 1;44(7):1295-304.

19. Ribas-Maynou J, Yeste M, Salas-Huetos A. The relationship between sperm oxidative stress alterations and IVF/ICSI outcomes: a systematic review from nonhuman mammals. Biology (Basel). $2020 \mathrm{Jul}$ 21;9(7):E178.

20. Goud PT, Goud AP, Diamond MP, Gonik B, Abu-Soud HM. Nitric oxide extends the oocyte temporal window for optimal fertilization. Free Radic Biol Med. 2008 Aug 15;45(4):453-9.

21. Marreiro D, Cruz KJ, Morais JB, Beserra JB, Severo JS, Soares de Oliveira AR. Zinc and oxidative stress: current mechanisms. Antioxidants (Basel). 2017 Mar 29;6(2):24.

22. Hemmens B, Goessler W, Schmidt K, Mayer B. Role of bound zinc in dimer stabilization but not enzyme activity of neuronal nitricoxide synthase. J Biol Chem. 2000 Nov 17;275(46):35786-91.

23. Jarosz M, Olbert M, Wyszogrodzka G, Młyniec K, Librowski T. Antioxidant and anti-inflammatory effects of zinc. Zinc-dependent NF-kB signaling. Inflammopharmacology. 2017 Feb;25(1):11-24.

24. Prasad AS. Discovery of human zinc deficiency: its impact on human health and disease. Adv Nutr. 2013 Mar 1;4(2):176-90.

25. Pisano M, Hilas $\mathrm{O}$. Zinc and taste disturbances in older adults: a review of the literature. Consult Pharm. 2016 May;31(5):267-70.

26. Walker CLF, Rudan I, Liu L, Nair H, Theodoratou E, Bhutta ZA, et al. Global burden of childhood pneumonia and diarrhoea. Lancet. 2013 Apr 20;381(9875):1405-16.

27. Skalny AV, Rink L, Ajsuvakova OP, Aschner M, Gritsenko VA, Alekseenko SI, et al. Zinc and respiratory tract infections: perspectives for COVID-19 (Review). Int J Mol Med. 2020 Jul;46(1):1726.

28. Perry DK, Smyth MJ, Stennicke HR, et al. Zinc is a potent inhibitor of the apoptotic protease, caspase-3: a novel target for zinc in the inhibition of apoptosis. J Biol Chem. 1997;272:18530-3.

29. Schoggins JW, Wilson SJ, Panis M, et al. A diverse range of gene products are effectors of the type I interferon antiviral response. Nature. 2011;472:481-5.

30. Meagher JL, Takata M, Gonçalves-Carneiro D, Keane SC, Rebendenne A, Ong H, et al. Structure of the zinc-finger antiviral protein in complex with RNA reveals a mechanism for selective targeting of CG-rich viral sequences. Proc. Natl. Acad. Sci. 2019;116(48):24303-9.

31. Ficarelli M, Antzin-Anduetza I, Hugh-White R, Firth AE, Sertkaya $\mathrm{H}$, Wilson $\mathrm{H}$, et al. $\mathrm{CpG}$ dinucleotides inhibit HIV-1 replication through zinc finger antiviral protein (ZAP)-dependent and independent mechanisms. J Virol 2020. 2020;94(6):e01337-19.

32. Wessels I, Maywald M, Rink L. Zinc as a gatekeeper of immune function. Nutrients. 2017;9:1286. 
33. Read SA, Obeid S, Ahlenstiel C, Ahlenstiel G. The Role of Zinc in Antiviral. Immunity. 2019 Jul 1;10(4):696-710.

34. Yao JS, Paguio JA, Dee EC, Tan HC, Moulick A, Milazzo C, et al. The minimal effect of zinc on the survival of hospitalized patients with Covid-19: an observational study. Chest. 2020 Jul 22;S00123692(20):31961-9.

35. Fallah A, Mohammad-Hasani A, Colagar AH. Zinc is an essential element for male fertility: a review of $\mathrm{Zn}$ roles in men's health, germination, sperm quality, and fertilization. J Reprod Infertil. Apr-Jun 2018;19(2):69-81.

36. Sengupta P, Banerjee R, Nath S, Das S. Banerjee S Metals and female reproductive toxicity. Hum Exp Toxicol. 2015 Jul;34(7): 679-97.

37. Yahfoufi ZA, Bai D, Khan SN, Chatzicharalampous C, KohanGhadr H, Morris RT, et al. Glyphosate induces metaphase II oocyte deterioration and embryo damage by zinc depletion and overproduction of reactive oxygen species. Toxicology. 2020 Jun;439: 152466.

38. Que EL, Duncan FE, Bayer AR, Philips SJ, Roth EW, Bleher R, et al. Zinc sparks induce physiochemical changes in the egg zona pellucida that prevent polyspermy. Integr Biol (Camb). 2017 Feb 20;9(2):135-44.

39. Zhang N, Duncan FE, Que EL, O'Halloran TV, Woodruff TK. The fertilization-induced zinc spark is a novel biomarker of mouse embryo quality and early development. Sci Rep. 2016 Mar 18;6: 22772.

40. Hanna LA, Clegg MS, Momma TY, Daston GP, Rogers JM, Keen CL. Zinc influences the in vitro development of peri-implantation mouse embryos. Birth Defects Res A Clin Mol Teratol. 2003 Jun;67(6):414-20.

41. Hurley L, Shrader R. Abnormal development of preimplantation rat eggs after three days of maternal zinc deficiency. Nature. 1975;25: 427-9.

42. Haase H, Rink L. Functional significance of zinc-related signaling pathways in immune cells. Annu Rev Nutr. 2009;29:133-52.

43. Golub MS, Keen CL, Gershwin ME, Hendrickx AG. Developmental zinc deficiency and behavior. J Nutr. 1995;125: 2263S-71S.

44. Hurley LS, Swenerton $\mathrm{H}$. Congenital malformations resulting from zinc deficiency in rats. Proc Soc Exp Biol Med. 1966;123:692-6.

45. Cavdar AO, Babacan E, Asik S, Arcasoy A, Ertem U, Himmetoglu $\mathrm{O}$, et al. Zinc levels of serum, plasma, erythrocytes and hair in Turkish women with anencephalic babies. Prog Clin Biol Res. 1983;129:99-106.

46. Chiang C, Litingtung Y, Harris MP, Simandl BK, Li Y, Beachy PA, et al. Manifestation of the limb prepattern: limb development in the absence of sonic hedgehog function. Dev Biol. 2001;236:42135 .
47. Uriu-Adams JY, Keen CL. Zinc and reproduction: effects of zinc deficiency on prenatal and early postnatal development. Birth Defects Res B Dev Reprod Toxicol. 2010 Aug;89(4):313-25.

48. Chia SE, Ong CN, Chua LH, Ho LM, Tay SK. Comparison of zinc concentrations in blood and seminal plasma and the various sperm parameters between fertile and infertile men. J Androl. 2000;21(1): 53-7.

49. Eggert-Kruse W, Zwick EM, Batschulat K, Rohr G, Armbruster FP, Petzoldt D, et al. Are zinc levels in seminal plasma associated with seminal leukocytes and other determinants of semen quality? Fertil Steril. 2002;77(2):260-9.

50. Roy B, Baghel RPS, Mohanty TK, Mondal G. Zinc and male reproduction in domestic animals: a review. Indian J Anim Nutr. 2013;30(4):339-50.

51. Hunt CD, Johnson PE, Herbel J, Mullen LK. Effects of dietary zinc depletion on seminal volume and zinc loss, serum testosterone concentrations, and sperm morphology in young men. Am J Clin Nutr. 1992;56(1):148-57.

52. Croxford TP, McCormick NH, Kelleher SL. Moderate zinc deficiency reduces testicular Zip6 and Zip10 abundance and impairs spermatogenesis in mice. J Nutr. 2011;141(3):359-65.

53. Saleh RA, Agarwal A, Kandirali E, Sharma RK, Thomas AJ, Nada EA, et al. Leukocytospermia is associated with increased reactive oxygen species production by human spermatozoa. Fertil. Steril. 2002;78:1215-24.

54. Liu J, Cao R, Xu M, Wang X, Zhang $\mathrm{H}, \mathrm{Hu} \mathrm{H}$, et al. Hydroxychloroquine, a less toxic derivative of chloroquine, is effective in inhibiting SARS-CoV-2 infection in vitro. Cell Discov. 2020;6:16.

55. Tian X, Anthony K, Neuberger T, Diaz FJ. Preconception zinc deficiency disrupts postimplantation fetal and placental development in mice. Biol Reprod. 2014 Apr 25;90(4):83.

56. Aldhaheri SR, Jeelani R, Kohan-Ghadr H, Khan SN, Mikhael S, Washington C, et al. Dimercapto-1-propanesulfonic acid (DMPS) induces metaphase II mouse oocyte deterioration. Free Radic Biol Med. 2017 Nov;112:445-51.

57. Hajjar T, Soleymani F, Vatanchian M. Protective effect of vitamin $\mathrm{C}$ and zinc as an antioxidant against chemotherapy-induced male reproductive toxicity. J Med Life. 2020 Apr-Jun;13(2):138-43.

58. Azizollahi G, Azizollahi S, Babaei H, Kianinejad M, Baneshi MR, Nematollahi-mahani SN. Effects of supplement therapy on sperm parameters, protamine content and acrosomal integrity of varicocelectomized subjects. J Assist Reprod Genet. 2013 Apr;30(4):593-9.

Publisher's Note Springer Nature remains neutral with regard to jurisdictional claims in published maps and institutional affiliations. 